\title{
Promoting access to decent work: career counselors' experiences with career construction counseling
}

\author{
Kirsten Marie Dalene ${ }^{1}[\mathbb{D}$
}

Received: 30 December 2020 / Accepted: 26 January 2022 / Published online: 9 February 2022

(c) The Author(s) 2022

\begin{abstract}
This article is based on career counselors' experiences with how career construction counseling (CCC) can benefit clients, and the results are discussed according to the psychological perspective of decent work in the psychology of working theory (PWT). The article argues that CCC can promote access to decent work by creating inward and outward meaning making, which refer to internal anchoring promoting the will to change. Hence, CCC's focus on the individual, together with contextualization, is considered a strength regardless of culture. Additionally, the article suggests that career counselors may affect whether CCC ultimately promotes access to decent work.
\end{abstract}

Keywords Career construction counseling · Life design · Decent work

\section{Résumé}

Promouvoir l'accès à un travail décent: Les expériences des conseillerères en orientation professionnelle en matière de counseling de construction de carrière Cet article est basé sur les expériences des conseillerères en orientation professionnelle sur la façon dont le counseling de construction de carrière (CCC) peut bénéficier aux clientes, et les résultats sont discutés sur la base de la perspective psychologique du travail décent dans la psychology of working theory (PWT). L'article soutient que le CCC peut promouvoir l'accès à un travail décent en aidant au développement de sens interne et externe, qui font référence à l'ancrage interne favorisant la volonté de changer. Par conséquent, l'accent mis par la CCC sur l'individu ainsi que sa contextualisation, sont considérés comme une force, indépendamment de la culture. En outre, l'article suggère que les conseillerères en orientation professionnelle peuvent avoir une influence sur la mesure dans laquelle la CCC favorise à terme l'accès à un travail décent..

Kirsten Marie Dalene

kirsten.marie.dalene@usn.no

1 Department of Culture, Religion and Social Studies, University of South-Eastern Norway (USN), Drammen, Norway 


\section{Zusammenfassung}

Förderung des Zugangs zu menschenwürdiger Arbeit: Die Erfahrungen von Berufsberatern mit Career Construction Counselling Dieser Artikel basiert auf den Erfahrungen von Berufsberatenden, inwiefern Career Construction Counselling (CCC) Klienten zugutekommen kann. Die Ergebnisse werden unter Berücksichtigung der psychologischen Perspektive der menschenwürdigen Arbeit aus der Psychology of Working Theory (PWT) diskutiert. In dem Artikel wird argumentiert, dass CCC den Zugang zu menschenwürdiger Arbeit fördern kann, indem sie eine nach innen und außen gerichtete Sinngebung schafft, die sich auf eine innere Verankerung bezieht und den Willen zur Veränderung fördert. Daher wird der Fokus von CCC auf das Individuum, in Kombination mit der Kontextualisierung und unabhängig der Kultur, als Stärke angesehen. Darüber hinaus legt der Artikel nahe, dass Berufsberatende einen Einfluss darauf haben können, ob CCC letztlich den Zugang zu menschenwürdiger Arbeit fördert.

\section{Resumen}

Promoción del acceso al trabajo decente: experiencias de los orientadores profesionales con el asesoramiento en la construcción de carreras Este artículo se basa en las experiencias de los consejeros de carrera sobre cómo la consejería de construcción de carrera (CCC) puede beneficiar a los clientes, y los resultados se discuten de acuerdo con la perspectiva psicológica del trabajo decente en la psicología de la teoría del trabajo (PWT). El artículo plantea que el CCC puede promover el acceso al trabajo decente mediante la creación de significados hacia adentro y hacia afuera, y que se refieren al anclaje interno que promueve la voluntad de cambio. Por lo tanto, el enfoque de $\mathrm{CCC}$ en el individuo, junto con la contextualización, se considera una fortaleza independientemente de la cultura. Además, el artículo sugiere que los orientadores profesionales pueden influir si la CCC promueve en última instancia el acceso al trabajo decente.

\section{Introduction}

Career construction counseling (CCC), as one of multiple methodologies within the life design paradigm (Nota \& Rossier, 2015; Savickas et al., 2009), is claimed to be useful for clients seeking career counseling in the twenty-first century (Savickas, 2019b). Today's postmodern world of work is dominated by uncertainty and change resulting from increased globalization, rapid technological development, organizational restructuring, and an increasing number of temporary positions (Blustein et al., 2019b; Savickas, 2019b), exacerbated in 2020 by the global pandemic (Blustein et al., 2020). However, Savickas seems to place CCC into a greater context with the concepts of decent work and social justice only to a limited extent (cf. Savickas, 2013, 2015a, 2019b; Savickas et al., 2009). Exceptions can be found in Savickas's manual, where he writes, "There are normative boundaries and social constraints that both precede and exceed the client. 
Usually the best a client can do is to improvise and compose a life with the available resources and social supports." (Savickas, 2019a, p. 71).

Career counseling in general has been criticized for overlooking important areas related to decent work and social justice, such as social inclusion and equality (Patton \& McMahon, 2014), despite the fact that modern career counseling developed early in the twentieth century precisely in response to the struggle for social justice (Parsons, 1909; Plant \& Kjærgård, 2016). Hooley et al. (2018) claim that career counseling lost sight of its social roots when it became seen as a branch of psychology, where the individual became the primary focus and society, and social context were largely ignored. The life design paradigm has come under criticism for dismissing how sociopolitical and economic contexts affect clients' opportunities to make good career choices (Hooley et al., 2018; Irving et al., 2016, 2020). However, Blustein et al. (2015) point to life design and Savickas's career construction theory (CCT) as relevant to social inclusion, with a particular emphasis on contextualization, life roles, and the use of narratives to develop a meaningful work life.

Thus, to further explore the connection between CCC and decent work, this article illuminates career counselors' experiences with how CCC can benefit clients and follows this with a discussion of the results regarding the psychological perspective of decent work from the psychology of working theory (PWT) (Blustein et al., 2016; Duffy et al., 2016). This perspective focuses on how decent work can lead to work fulfillment and general well-being, referring to the satisfaction of three fundamental needs: (1) survival needs (resources such as food, shelter, and health care), (2) social connection and contribution needs in relation to a larger community, and (3) selfdetermination needs and the need for one's behaviors to be congruent with authentic and meaningful goals (Blustein et al., 2019a, p. 239).

The article is based on empirical findings from action research conducted by the author, with career counselors from different career counseling contexts in Norway, including school counselors and career counselors for adults. The career counselors received training in and explored $\mathrm{CCC}$ as an individual career counseling process with each other and with their respective clients. The immediate experiences and reflections of the career counselors, which were explored in multistage focus group interviews (Hummelvoll, 2008) throughout the action research, are analyzed using thematic analysis (Braun \& Clarke, 2006) to identify how they have experienced $C C C$ benefit clients. The findings are discussed through the psychological perspective of decent work to find answers to the following research question: Based on career counselors' understandings of and experiences with how CCC can benefit clients, how can CCC promote access to decent work?

Previous research on how CCC can benefit clients generally comprises client case studies, which are informative for understanding effects related to, e.g.: new realizations and revising the self (Cardoso et al., 2016a), increased adaptability (Maree $\&$ Crous, 2012), achieving a greater awareness of oneself to autonomously develop one's career and life path (Di Fabio, 2016), having more confidence in one's choice of vocation (Cardoso et al., 2016b), and being able to create change in one's life (Cardoso et al., 2014; Maree, 2015). While there is little research on CCC from the perspective of career counselors, Rehfuss et al. (2011) conclude from a questionnaire survey career counselors to experience CCC identifying clients' life themes 
and assisting them in making meaningful career decisions. Some case studies of people from marginalized groups in terms of, for example, sexual orientation or ethnicity, may be related to this article's exploration of CCC in connection with access to decent work. These studies conclude that clients gain improved self-insight and an increased sense of personal authorship through CCC and suggest that CCC can also satisfy the needs of other minority groups (Maree, 2014, 2016). Additionally, Maree and Che (2018) find that CCC helps young people find positive aspects of their lives and set their own goals in the face of challenging economic conditions. However, there is a lack of research that explores the promotion of decent work through CCC based on career counselors' perspective of CCC.

Given the above, the intention of this article is to strengthen the knowledge base regarding how career counselors have seen CCC benefit clients, and the counselors' experiences will be used as the foundation for discussing whether CCC can promote access to decent work. Thorough theoretical elaborations of CCT (Savickas, 2021) and PWT (Blustein et al., 2019b) are beyond this article's scope, as it is limited to the practical CCT intervention (i.e., CCC) and the psychological perspective of decent work in PWT.

\section{Career construction counseling}

CCC is derived from CCT (Savickas, 2019b), which originated under the auspices of vocational psychology (Savickas, 2015a). CCC is one of multiple methodologies within the life design paradigm (Nota \& Rossier, 2015; Savickas et al., 2009), also referred to as the constructivist paradigm or perspective (Haug, 2016; Maree, 2011; McMahon, 2017; Norendal, 2018). CCT focuses on the self as a social actor, motivated agent, and autobiographical author and concentrates on self-construction through work and relationships (Savickas, 2019b). CCC consists of two sessions (Savickas, 2019a). In the first session, the career counselor conducts the career construction interview (CCI), a structured dialog to uncover life themes and provide new perspectives on the current transition. CCI, in addition to the counselor's ability to form relationships, prompt reflection, and encourage sense-making, constitutes the core of CCC (Savickas, 2019a). CCI consists of an initial question to elicit client's transition narrative, in addition to five main questions: (1) role-models / who you admired when you were growing up, (2) which television programs do you watch regularly, (3) current favorite story from a book or movie, (4) favorite saying or motto and (5) early recollections (Savickas, 2019b). After the first session, the counselor combines the client's micronarratives into a life portrait (macronarrative) related to challenges in the transition narrative, using the words of the client, to provide a new view of the transition and envision future possibilities (Savickas, 2019a). In the second session, the counselor retells the life portrait to make the client hear his or her own words, coinciding joint deconstruction and reconstruction of the life portrait to clarify meaning, and the client receives the completed version of the life portrait. Finally, the focus is on co-construction and action plans, where goals for further exploration and actions are set (Savickas, 2019a, 2019b). Savickas (2015c) also calls this counseling process a biographical bricolage. 


\section{A psychological perspective of decent work}

Similar to Savickas's theory, PWT has a clear basis in psychology. However, it is presented as an interdisciplinary theory based on psychological, social, and economic aspects and thus aims to offer a broader approach than that provided by traditional career theories (Duffy et al., 2016). The theoretical work of Blustein et al. (2016) addresses "critiques of traditional discourses in vocational psychology and career development, which had privileged the lives of individuals with relative access to stable jobs" (Blustein et al., 2019b, p. 4). PWT appears to be a psychological working life theory that focuses on individuals' ability to secure decent work, particularly people who live in poverty, are members of marginalized groups, or experience limitations in their own context.

PWT's perspective on decent work is based on the standards developed by the International Labor Organization through its "Decent Work Agenda" (ILO, 2008) and has been developed with a psychological focus (Blustein et al., 2016; Duffy et al., 2016). The theory provides a comprehensive explanation of predictions for securing decent work, as well as mediating and moderating variables. This article mainly considers the ways PWT presents the satisfaction of the three abovementioned fundamental needs related to decent work. The article also assumes PWT's moderator variable economic conditions (Duffy et al., 2016, p. 138), as this variable may be connected to the critique of CCC that the intervention does not take socioeconomic conditions into account. These needs and constraints are the framing factor when the career counselors' experiences with CCC are discussed in relation to decent work.

\section{Methods}

\section{Participants}

The 16 participants in the action research were career counselors from different contexts in Norway who were recruited through strategic selection (Brottveit, 2018) via professional networks such as student groups and conferences and invited to take part in CCC training and testing. It was made clear that critical input was welcome if the participants were interested in learning and experimenting with the intervention. The number of participants was chosen so they could be divided into two fixed groups, youth counselors and adult counselors, with a maximum of eight members in each (Hummelvoll, 2008). All 16 participants satisfied the selection criteria: they had work experience as career counselors in at least a half-time position for at least two years, had formal competence in counseling, good knowledge of counseling skills, and were motivated to participate. Eight worked as youth counselors in middle school or upper secondary school with clients (aged 13 to 19), and eight worked with adults (aged 19 to 67, the ordinary retirement age in Norway) in career centers, within the Norwegian welfare system (NAV), at companies for unemployed people or people on sick leave, or as self-employed counselors. The participants were told 
to read an article about CCC (Norendal, 2018) and Savickas's life design counseling manual (Savickas, 2015b) before the first session in the action research.

Three of the participants had previous experience with CCC, three of the other participants expressed some skepticism about it, and all participants were interested in learning more about CCC. However, as all participants chose to spend time and effort to participate in this action research, it is reasonable to assume that they were more interested in CCT/CCC than the average career counselor in Norway, which should be remembered when considering the research results. Indeed, all the participants (even the sceptics) reported increased interest and enthusiasm for the intervention at the end of the action research period. This change may be related to the value of the research design's (cooperative inquiry) extended epistemology (Heron \& Reason, 2008) and is further discussed in another article (Dalene, under review). The action research was approved by the Norwegian Centre for Research Data (NSD), and all participants signed the informed consent form, which also mentioned their ability to withdraw from the action research at any time. The participants have been given fictitious names in the article and are referred to as career counselors in both the findings and the discussion to emphasize this article's perspective on CCC.

\section{Procedures}

The action research was carried out using a modified form of cooperative inquiry (Heron \& Reason, 2006) as the research design, which cycles between reflection and action. Multistage focus group interviews, a relevant method in action research based on a cooperative inquiry perspective (Hummelvoll, 2008), were chosen as the main research method. These interviews focus on the same group exploring and reflecting on a certain problem, theme or phenomenon throughout several meetings with the researcher, who serves as a moderator; the theme gradually becomes enriched by new perspectives and nuances added from the participants' practices and experiences (i.e., actions) in the periods between the interviews (Hummelvoll, 2008). This method resembles cooperative inquiry groups (CIGs) (Heron \& Reason, 2006), although in CIGs, the participants take turns acting as the moderator, whereas in multistage focus group interviews, the researcher functions as the moderator and leads the knowledge process through the whole research period (Hummelvoll, 2008).

This action research consisted of three all-day meetings over a period of three months, with the first meeting lasting two days. In these meetings, the participants received joint instruction in $\mathrm{CCC}$, trained in triads on using $\mathrm{CCC}$ (actions 1 and 3 ), wrote reflection logs and participated in multistage focus group interviews. During the two intervening periods, each participant completed at least one individual career counseling process using CCC with a client at the counselors' workplace (actions 2 and 4). The counselors experimented with CCC with their clients ranging from 17 to 55 years old. The author worked as the research moderator and training manager, while a colleague participated in all meetings, functioning as an observer and critical consulting support throughout the action research. 
The empirical material used in this article consists of transcribed audio recordings from the multistage focus group interviews, that is, three recordings of each of the two focus groups. Semi-structured interview guides were designed to solicit all the participants' reflections and experiences with CCC and was adjusted between each interview to follow up from the previous focus group interview with the same group (hence multistage). It should be noted that the term "decent work" was not a part of the interview guides; however, the aforementioned criticism of the intervention (Irving et al., 2016) was discussed with the participants. A professional service transcribed the audio recordings, whereupon the author did the necessary proofreading and carried out quality checks.

\section{Data analysis}

In light of the article's research question and the empirical findings being analyzed, the thematic analysis developed by Braun and Clarke (2006) was chosen as the analytical strategy. This analysis has six phases (Braun \& Clarke, 2006): (1) become familiar with the data, (2) generate initial codes, (3) search for themes, (4) review themes, (5) define and name themes, and (6) produce the report. After having read all the transcripts (phase 1), the author undertook the preliminary coding according to the analytical question: Based on the career counselors' experiences and reflections, how can CCC benefit clients? (phase 2). Statements concerning which clients $C C C$ is suitable for were also marked due to their relevance for the economic conditions variable (Duffy et al., 2016). In the first phases, the analysis distinguished between youth and adult counselors. However, when this technique revealed no remarkable differences between the groups related to the analytical question, the analysis process continued with the purpose of observing the career counselors' experiences with CCC's benefits for clients across age groups.

Phase 3 consisted of finding relationships between the preliminary codes or statements and sorting them into possible themes. These themes were identified from patterns and meanings that emerged among the coded statements, supplemented by the rationale that 'the 'keyness' of a theme is not necessarily dependent on quantifiable measures-but rather on whether it captures something important in relation to the overall research question" (Braun \& Clarke, 2006, p. 82). In phase 4, the sorting was reviewed, the statements were read again, and code and statement replacements were made as necessary. The aim was to identify between three and six final themes (Braun et al., 2015), and after this last round of review, four main themes were identified. Then, the themes were further defined by giving them suitable names (phase 5): (1) self-insight, meaning and coherence in life, (2) engagement, direction and contribution, (3) different people and contexts, and (4) the role of the career counselor. Phase 6 involved the presentation of the findings and the discussion, which follow below. 


\section{Reflexivity and validity}

Reflexivity in the researcher role and a transparent presentation of the researcher's preunderstanding and choices during the process are important elements in validating qualitative research (Finlay, 2002; Levin, 2017; Reason, 2006). Bearing this in mind, as the researcher, I made my preunderstanding clear in the researcher log prior to the start of the action research; I was enthusiastic about how the intervention could effectively assist clients' career challenge, however also somewhat skeptical about how it could be used by career counselors in Norway. This was partly because the intervention appears to require comprehensive training and to border therapy. With this awareness of my preunderstanding, following conversations with my colleague, I determined that I should aim to not lead the participants in any specific direction in the action research. In the analysis process, I attempted to let the overarching research question for this article and the abovementioned analytical question guide the coding and identification of the themes.

Thus, this article can be criticized for not integrating a double-bind analysis to validate the results. However, Reason (2006) claims that action research is a process filled with different choices, where quality largely depends on conscious decisions and transparency, which coincides with my goal: "The best we can do is to offer our choices to our own scrutiny, to the mutual scrutiny of our coresearchers, to the wider community of inquirers, and to the interested public at large. Quality rests not so much on getting it right but on stimulating open discussion" (Reason, 2006, p. 199). Further limitations of the study are outlined at the end of the discussion section in this article.

\section{Findings}

\section{Self-insight, meaning and coherence in life}

All the career counselors agree that CCC is very effective in creating internal changes in the clients, and this theme can be summarized as inward meaning making. The starting point appears to be that $\mathrm{CCC}$ creates an efficient process, primarily through asking effective and somewhat surprising questions. Christian says, "They [the questions] were odd at first, and then the students come back and tell me that they were really... 'They opened my eyes in a different way' and 'They sort of set me up". The counselors also stated that the questions regarding the client's life portrait and its subsequent recitation helped them quickly determine the core of the client's challenge.

The career counselors agree that reciting the client's story in the second session created a special self-insight and strength among clients, described by Kristin as:

...the source of the qualities, in a way comes from these narratives about my aunt and granny and best friend. They embrace your whole life. There's noth- 
ing 'out there' that I need to choose, but it's in a way...it actually comes from the inside out.

Peter describes some of the same experiences when talking about his first experience using CCC with a client: "She knows what she has said, but it's clearer when I read through it and say: 'You said this and that.' So, through the retelling, it becomes credible in a way." During the action research period, the counselors were also encouraged to experiment with CCC or various parts of the intervention in different ways. Mette describes her experience with this after trying out parts of CCI in regular client interviews with students:

And then I talked with those teachers later and then they say: "What have you done? They [the students] come down radiant, so pleased with themselves and are quite ... They were sort of 'have to go to a meeting with the counselor,' and then they come out and are so satisfied and happy!' Everyone, both boys and girls. So, it's true that it gave them something, that they gained an insight into themselves which they probably felt was useful.

The counselors give varying reflections on how CCC may provide meaning and anchoring. Trude talks about how CCC gives "a sort of meaning-making hat," and Martin says that CCC "creates meaning." Kristin calls it an anchor: "They get an anchor. (...) Then, they have, in a way, an anchor for where they are today, what it is related to, who they are, and where they envision that they are going." Mette talks about something similar, saying that it must "settle in you" to give meaning:

Because I think that many people can tell you what you're good at, and what you can do and all that. But if you don't believe it yourself, it won't lead to any action. Then, back to this interview we were watching [where Savickas counsels a young man], he repeats it again and again and makes him [the young man] repeat it and makes him say it. That it must somehow settle in you. You feel that this is my way, or this is what I can contribute, or this gives my life meaning. And if you don't believe it or feel that it's right, then it doesn't help that we have the key or tell you that 'You're very good at this.' It might be true, it may be just what we see, but it must come from the inside, or it will become only a very boring life and a difficult life for most, if you don't like what you do and don't believe it is right for you.

Several of the counselors reflect on how CCC provide wholeness and coherence within clients' lives, described here by Sara, who believes that career counselors cannot just concentrate on clients' careers: "Because that part of life [e.g., careers] is never isolated from the other parts of life. And I think that CCC really gets this point that we must think holistically to make good choices when it comes to career choices." In sum, all the counselors agree that in terms of inward meaning making, $\mathrm{CCC}$ is an efficient intervention that quickly gets at the core of the matter, mostly due to its "odd" and surprising questions. They find that reciting the clients' stories to them helps the clients obtain new self-insights in a credible way, which further leads to anchoring and meaning making. Some of the counselors also find that CCC 
helps them see life as a comprehensive whole and that clients may discover new connections using CCC.

\section{Engagement, direction and contribution}

The essence of this theme can be understood as outward meaning making. The career counselors describe this theme using a variety of terms. Some of them reflect on how CCC helps the clients identify their commitments, particularly through the question about early recollections. Kristin says, "Those early recollections show engagement and give perspectives on the situation they are in today." Alternatively, Sara notes that "this question really illuminates what the challenge has been and also the engagement," and Trude talks about direction: "I feel that it's an intervention that in a way, like, elegantly gives the client... or I got the impression myself, as a client, something like an overarching direction and meaning."

Still others describe how CCC gives hope, and the process may create the will to change, as Mette mentions: "If you say, 'If you want to change something in your life, the force must come from within. It must come from yourself if you are to make a big change', this is what life design is all about." The counselors also note that CCC can help clients become more aware of what contributions they want to make, as Hilde says:

There are many who end up in such new settings, where things change, necessitating that they find a way back to "what I am and who I am in all this, and what I can contribute.' So, I think many would benefit from having this type of counseling.

The results indicate that by getting to know oneself and finding engagement and direction, clients may allow the effect of their contributions to stretch beyond themselves. To summarize, outward meaning making was described by the counselors with a variety of terms, all of which indicated that CCC benefits clients' engagement, direction in life, and awareness of their own contributions to something larger than themselves.

\section{Different people and contexts}

The counselors have varying ideas about whom CCC is most suitable for. Some of them believe that it will work well for people who underestimate themselves or are more introverted. Hilde says:

No, it's difficult to use it with young people, you might say, because they don't know anything about themselves. But then I think that this may actually be an opener, you know (...) and that you, in a way ... Yes, it's a way of talking about yourself that is not dangerous, because you tell things about yourself without knowing that you do.

Other career counselors believe that CCC is suitable for clients who are stuck or have limited opportunities. However, Christian sees it to be the opposite, saying, 
"Sometimes when you want to give someone something extra, or you see that someone needs it. [There is] no need to use it just with weak students. Very strong students may also need something extra."

The counselors were made aware of and were asked about the criticism that CCC is too focused on the individuals themselves and does not adequately consider various socioeconomic contexts. Most counselors comment that they experience the individual focus in a positive way. Sara says:

I think that when we use inner motivation, when we get a grip on it, then we may also achieve something that is useful for society. So, I don't think there's a contradiction between having an individual focus and maybe also being useful collectively.

Thomas asserts that there can never be too much individual focus: "It's positive regardless." However, Thomas and others find that the intervention is most suitable in the Western world, and this double perspective among the counselors emerges clearly in the conversation between Thomas and Mette:

Thomas: But in Norwegian society, where you have quite a lot of options, bearing in mind that education is more or less free, it's simpler to apply such an intervention like this. But it's also clear that the intention of Savickas and his 'conspirators,' to put it like that, was that it's an intervention that can be used in all contexts, although I doubt that's possible.

Mette: I think I disagree. Now, I'm just reacting immediately without having thought very much about it. I'm thinking aloud right now. I disagree because I think just because it's individual-based, then it frames the person you are, in the situation there and then, regardless your background and where you come from. And the role of the counselor is to address what is here and counsel based on the background and preconditions of everyone. Then, you can highlight... This is not about getting everybody employed, everybody into education, everybody into... it's about feeling that you master things in life. That's how I see it. It's about making an individual reality-oriented and aware of the qualities they can use and work with to have a good life.

When Kristin and Julie reflect on this, they point out how using stories and narratives is perhaps quite common and natural in some non-Western cultures. Therefore, they find that CCC should not be rejected as an irrelevant intervention outside Western countries. Julie states to "not be so terrified of highlighting what many cultures would say, 'Yes, of course, we've been doing this for a thousand years"'.

In sum, this theme shows that the counselors believe that CCC can be suitable for individuals with different challenges and constraints as well as for those who need something extra in a more positive sense because the intervention focuses on how to master life. Most find it empowering that $\mathrm{CCC}$ has a strong individual focus, but they disagree as to whether the intervention would be useful in non-Western countries. At the same time, the intervention's emphasis on storytelling is highlighted as a possible universal strength. 


\section{The role of the career counselor}

The analysis results reveal that a few of the career counselors talk about their own role and importance in relation to both how CCC can benefit clients and whom it is useful for. The rationale for pointing out this theme in particular is its importance and possible implications for the article's research question (Braun \& Clarke, 2006, p. 82).

The career counselors who raise this issue talk about it in different ways. Some of them believe that to be able to use CCC at all, the career counselor needs to both gain a thorough understanding of the intervention and wanting to use it, here in the words of Kristin: "It could be that the criticism [of CCC] is made because the critics have not studied the intervention and don't understand it. Haven't tried it, haven't experienced it". Hilde says:

I think that this is not something you can force someone to use. You can't tell your colleagues if you become the boss that 'now you have to start doing life design', because this is something you really need to want to do.

Trude points out that a constructivist intervention such as CCC may help career counselors free themselves from the expert perspective and instead adopt the role of an equal collaborator with the client. She says:

In terms of how to create a standard for what is good career counseling, there are some principles here that are useful to include for new career counselors or other career counselors who don't have this kind of experience - a bit like 'the old school' for example, who want to continue to give advice.

Christian talks about the role of the career counselor regarding expanding and contextualizing the client's perspective:

But I think that this, again, is very much about the career counselor. And the perspective and the context you chose to provide. Particularly in ... perhaps not in the introductory phase, but in the feedback, you must try to put it in the context that you are part of a bigger picture.

Hence, this theme refers to what is needed for a career counselor to use the intervention, what career counselors can learn about their role by using such an intervention, and how career counselors can use their role to expand their client's perspective.

\section{Discussion}

The findings raise three questions, strongly related to the research question, that will be addressed in this section. The first refers to the link between inward meaning making and outward meaning making: In what way can the two "meaning movements" of CCC promote access to decent work? The next question refers to people and contexts: For whom will CCC be able to promote access to decent work? Finally, the article will discuss the career counselors' role: How can career 
counselors affect CCC to promote access to decent work? As previously mentioned, these questions will be discussed in light of the economic conditions variable (Duffy et al., 2016) and the satisfaction of the three fundamental needs of decent work: (1) survival needs, (2) social connection and contribution needs, and (3) self-determination needs and the need for one's behaviors to be congruent with authentic and meaningful goals (Blustein et al., 2019a).

\section{In what way can the two "meaning movements" of CCC promote access to decent work?}

Conveniently, McMahon and Watson (2020) recently questioned what is expected from career counseling in terms of promoting access to decent work. When the findings in this article are assessed in regard to the satisfaction of the three needs related to decent work (Blustein et al., 2019a), it becomes clear that CCC does not directly promote satisfaction of fundamental "survival needs". On the other hand, it can be claimed that by contributing to other needs relating to decent work, CCC also helps satisfy fundamental needs, however CCCs primary contribution seems to be on another level. Nor can the findings be connected primarily to the satisfaction of the needs relating to "social connection", i.e., through the clients' job. Nevertheless, this may partly be due to the limitations of this study when exploring CCC as an individual intervention; research on group-based use of CCC might reach other conclusions on this issue.

In return, the analysis of the reflections and experiences of the career counselors seems to be specifically linked to decent work as "self-determination needs," "the need for one's behaviors to be congruent with authentic and meaningful goals," and "contribution needs" (Blustein et al., 2019a). The findings confirm case study research on how CCC can benefit clients (e.g., Cardoso et al., 2016a, 2016b; Di Fabio, 2016), described by the career counselors in this study as increased selfinsight, meaning, anchoring and coherence in life, which were summarized during analysis as inward meaning making. However, with the perspective on decent work with emphasis on self-determination, meaning and the need to contribute, the link between inward meaning making and the findings revealing increased engagement, direction and contributions, which are summarized in the analysis as outward meaning making, shows the unique way CCC may promote access to decent work. These findings illuminate how the career counselors experience CCC to lead their clients a step further to find their own engagement, clarify their direction, and become aware of what they want to contribute. This is in line with the understanding that people need to be engaged in meaningful activities and have a sense of contributing to something greater than themselves in order to reach the goal of securing decent work (Duffy et al., 2016).

In comparison, the counseling model in PWT, the psychology of working counseling (PWC) (Blustein et al., 2019a) offers an organizing framework to help clients change their environment and coping strategies by discussing relevant themes with their counselor. However, this article demonstrates that $\mathrm{CCC}$ can promote access to decent work in a different way than PWC. In fact, the findings show that CCC 
creates the will to change by first recognizing one's own internal anchoring. To repeat the words of Mette: "If you say, 'If you want to change something in your life, the force must come from within. It must come from yourself if you are to make a big change,' this is what life design is all about." This willingness to change does not necessarily mean that the conditions surrounding the client will improve, which is the goal of Blustein and et al., (2019a) in developing PWT into a "theory of change" that deals with both the individual and the system. However, CCC may create the motivation to do something about those aspects of one's life that one is able to change. This is in line with the statement from Savickas (2019b, p. 34) emphasizing the possibility for clients during CCC to "actively master what they have passively suffered."

\section{For whom will CCC promote access to decent work?}

Based on the findings in this article, CCC generally appears to be a useful intervention for a broad range of clients with different counseling needs, including both people with extra challenges and people being ambitious about their careers. The findings regarding the latter category correspond with the findings in a case study by Maree (2018), where he conclude that CCC can satisfy the needs of talented individuals by identifying life themes and finding meaning and purpose within their career choices. In regard to the economic constraints variable (Duffy et al., 2016), connected to the criticism against CCC (Irving et al., 2016, 2020), this article's findings are ambiguous. Some counselors claim that a strong focus on the individual is positive, regardless of the context and economic conditions, while others doubt the intervention to be suitable outside of Western countries.

However, earlier research has pointed out the value of CCC across contexts and cultures (Maree \& Che, 2018; Winslade, 2011). Bhalla and Frigerio (2020) were the first to conduct a study on CCC in India, concluding that it can be an effective career counseling intervention in non-Western countries-if consideration is given to the cultural values and the collectivist orientation of the clients. This is in line with Savickas (2019a, p. 28) own description of the goal of CCI's question 3 (favorite story): "understand the stories or cultural scripts that a client may be using to envision the transition outcome." Tien (2015) also discusses cultural perspectives on life design, emphasizing that everyone is the author of his or her own story but that individuals must also be aware of their own social context. The career counselors' reflections on the universality of narratives in this article touch on the opportunities found in narrative career counseling in general, which is also underlined by Cochran (2011, p. 18) when he writes: "Story is a human universal, and by taking a multicultural perspective, innovations are likely to arise."

Nevertheless, one does not need to travel beyond the West to find people with difficult economic conditions. Blustein et al. (2015) claim that in addition to consider relevant education and occupation information, career counseling for the poor and people from the lower social classes must also include the exploration of the self; they further assert that life design models are useful in this respect: 
(...) in that they involve projective and narrative means of articulating clients' life stories, which are inherently relativistic with respect to cultural assumptions about work. (...) These stories, when discussed in the counseling process, can help clients envision a future that includes their most meaningful aspirations (Blustein et al., 2015, pp. 249-250).

This is confirmed by the findings in this article revealing how the career counselors found the impact of retelling the clients' own stories to solicit engagement and meaning relating to the clients' work and life. Additionally, Ribeiro (2020) claims that psychology can contribute to decent work studies by offering a psychosocial and contextualized decent work view, which also points to psychologically based interventions such as CCC.

\section{How can career counselors affect CCC to promote access to decent work?}

The findings in the analysis reveal underlying issues related to career counselors' role in general, which may affect whether CCC ultimately promotes access to decent work. Some of the career counselors believe the career counselor must be willing to use the intervention and may even benefit from being counseled with CCC themselves to better understand the intervention and its underlying intentions. CCC is a comprehensive and relatively time consuming intervention (Savickas, 2019a), and it appears that the career counselors in this study find that it is necessary to believe in this intervention to consider it appropriate for clients.

The relevance to this article's research question is quite clear in one of the career counselor's statements about the need for career counselors to contextualize for the client. This aligns with Savickas's argument: "With a commitment to social justice, counselors encourage client volition to push against normative boundaries and social constraints to achieve for themselves, and maybe others, the best possible choice and most vital life design." (Savickas, 2019a, pp. 71-72). Furthermore, this is in line with the study by Tian et al. (2020), in which it was found that the techniques applied by career counselors in a CCC process may affect the clients' reflection and will to change.

From an overarching perspective, these findings connect with career counselors' mandate and the purpose of career counseling. As noted by McMahon and Watson (2020, p. 7):

At the most fundamental level, it is possible that the decent work agenda may stimulate the critical consciousness of career counsellors at an individual and collective level and encourage reflection on its role and its position in relation to socio-political institutions, clients, and political and economic agendas.

To affect CCC to promote access to decent work, this article's research suggest a need for career counselors to both believe in and comprehend the underlying intentions of CCC and be able to contextualize for clients, in the purpose of clients' work fulfillment and well-being in both work and life, as presented by Duffy et al. (2016) and Blustein et al., (2019a). 


\section{Limitations and recommendations for future research}

As mentioned in the methods section, as a researcher, I have my own preunderstanding of CCC. Despite being aware of this, I acknowledge that it may have influenced the career counselors in the action research and my analysis of the empirical data. The fact that the data have been analyzed by only one coder also limits the validity of the results. Other researchers might have identified other themes from the same empirical data, highlighted other discussions or reached other conclusions. Additionally, some career counselors dropped out of the study. All 16 career counselors joined the initial focus group interview (FG1); ten took part in FG2, and eight took part in FG3. The dropouts were explained as being due to time pressure or illness. The ten career counselors who participated in most of the research had specific backgrounds and competences, so their experiences with CCC cannot be related to all career counselors. The action research included a discussion of well-known critiques of CCC but did not directly address the notion of "decent work"; furthermore, the clients who tried CCC were not selected from marginalized group, nor as individuals living under difficult economic conditions, which also may limit the findings.

To obtain further knowledge about how CCC can promote access to decent work, more research, both from clients' and career counselors' perspectives, is required in developing countries as well as in Western countries with clients living below the poverty line or who have limited choices. Future research should address how an individual's will to change can be fostered through CCC, which may lead to persistent changes in promoting decent work for clients, preferably through sustained follow-up studies after the CCC process is completed. This echoes the question asked by Blustein et al. (2019a, p. 251): "How does change in individuals affect the ways in which they relate to systems?" Additionally, further exploration of the role of career counselors in promoting access to decent work through CCC is needed.

\section{Conclusion}

The article has shown that based on career counselors' experiences with how CCC can benefit clients, CCC does not primarily promote access to decent work in line with survival needs, social connections or changes in systems and society. Nevertheless, the findings reveal that CCC can promote securing decent work in terms of self-determination needs and congruent behavior with authentic and meaningful goals, in addition to contribution needs. The article argues CCC may create an effective career counseling process that yields inward meaning making in terms of increased self-insight, meaning, anchoring and coherence in life, which in turn leads to outward meaning making with increased engagement, clarified direction and an awareness of one's contributions. This unique way of promoting access to decent work is due to the way CCC may contribute to the client's recognition of his or her own internal anchoring, which in turn may sparks the client's motivation to make changes in those aspects of one's life that one is able to change; in addition to make the client aware of what he or she wants to contribute. 
The article further underlines that the career counselors in the study find CCC to be useful for a broad range of clients, even though the results diverge when economic conditions and the use of CCC across contexts and cultures are considered. However, the view that storytelling and narration have universal value is highlighted in the results, implying that $\mathrm{CCC}$ interventions may also be suitable for promoting access to decent work regardless of countries and cultures, when the individual focus of $\mathrm{CCC}$ is combined with contextualizing. Finally, the article suggests that career counselors may affect whether CCC ultimately promotes access to decent work through believing in the underlying intentions of CCC together with providing contextualization for the clients.

Funding Open Access funding provided by University Of South-Eastern Norway. Performed as part of a Ph.D. study at USN.

Data availability Data is stored according to the guidelines that apply to USN and are not available to others. My reference number at the Norwegian Centre for Research Data (NSD): 60785.

Code availability Not applicable.

\section{Declarations}

Conflict of interest The author declares that they have no conflict of interest.

Open Access This article is licensed under a Creative Commons Attribution 4.0 International License, which permits use, sharing, adaptation, distribution and reproduction in any medium or format, as long as you give appropriate credit to the original author(s) and the source, provide a link to the Creative Commons licence, and indicate if changes were made. The images or other third party material in this article are included in the article's Creative Commons licence, unless indicated otherwise in a credit line to the material. If material is not included in the article's Creative Commons licence and your intended use is not permitted by statutory regulation or exceeds the permitted use, you will need to obtain permission directly from the copyright holder. To view a copy of this licence, visit http://creativecommons.org/licen ses/by/4.0/.

\section{References}

Bhalla, A., \& Frigerio, G. (2020). Career counselling with life design in a collectivist cultural context: An action research study. Journal of the National Institute for Career Education and Counselling, 45, 68-76. https://doi.org/10.20856/jnicec.4509

Blustein, D. L., Duffy, R., Ferreira, J. A., Cohen-Scali, V., Cinamon, R. G., \& Allan, B. A. (2020). Unemployment in the time of COVID-19: A research agenda. Journal of Vocational Behavior. https://doi. org/10.1016/j.jvb.2020.103436

Blustein, D. L., Kenny, M. E., Autin, K., \& Duffy, R. (2019a). The psychology of working in practice: A theory of change for a new era. Career Development Quarterly, 67(3), 236-254. https://doi.org/10. 1002/cdq. 12193

Blustein, D. L., Kenny, M. E., Di Fabio, A., \& Guichard, J. (2019b). Expanding the impact of the psychology of working: Engaging psychology in the struggle for decent work and human rights. Journal of Career Assessment, 27(1), 3-28. https://doi.org/10.1177/1069072718774002

Blustein, D. L., Kozan, S., Connors-Kellgren, A., \& Rand, B. (2015). Social class and career intervention. In P. J. Hartung, M. L. Savickas, \& W. B. Walsh (Eds.), APA handbook of career intervention 
(Vol. 1: Foundations) (pp. 243-257). American Psychological Association. https://doi.org/10.1037/ 14438-014

Blustein, D. L., Olle, C., Connors-Kellgren, A., \& Diamonti, A. J. (2016). Decent work: A psychological perspective. Frontiers in Psychology, 7, 407. https://doi.org/10.3389/fpsyg.2016.00407

Braun, V., \& Clarke, V. (2006). Using thematic analysis in psychology. Qualitative Research in Psychology, 3(2), 77-101. https://doi.org/10.1191/1478088706qp063oa

Braun, V., Clarke, V., \& Rance, N. (2015). How to use thematic analysis with interview data. In A. Vossler \& N. Moller (Eds.), The counselling and psychotherapy research handbook (pp. 183-197). Sage. https://doi.org/10.1002/capr.12031

Brottveit, G. (2018). Vitenskapsteori og kvalitative forskningsmetoder: Om å arbeide forskningsrelatert [Theory of science and qualitative research methods: About working research-related]. Gyldendal Akademisk.

Cardoso, P., Duarte, M. E., Gaspar, R., Bernardo, F., Janeiro, I. N., \& Santos, G. (2016a). Life design counseling: A study on client's operations for meaning construction. Journal of Vocational Behavior, 97, 13-21. https://doi.org/10.1016/j.jvb.2016.07.007

Cardoso, P., Gonçalves, M. M., Duarte, M. E., Silva, J. R., \& Alves, D. (2016b). Life design counseling outcome and process: A case study with an adolescent. Journal of Vocational Behavior, 93, 58-66. https://doi.org/10.1016/j.jvb.2016.01.002

Cardoso, P., Silva, J. R., Gonçalves, M. M., \& Duarte, M. E. (2014). Narrative innovation in life design counseling: The case of Ryan. Journal of Vocational Behavior, 85(3), 276-286. https://doi.org/10. 1016/j.jvb.2014.08.001

Cochran, L. (2011). The promise of narrative career counseling. In K. Maree (Ed.), Shaping the story: A guide to facilitating narrative career counselling (pp. 7-19). Sense. https://doi.org/10.1163/97890 04406162_003

Dalene, K. M. (under review). Career counselors' experiences of early recollections in career construction counseling. The Career Development Quarterly.

Di Fabio, A. (2016). Life design and career counseling innovative outcomes. Career Development Quarterly, 64(1), 35-48. https://doi.org/10.1002/cdq.12039

Duffy, R., Blustein, D. L., Diemer, M. A., \& Autin, K. (2016). The psychology of working theory. Journal of Counseling Psychology, 63(2), 127-148. https://doi.org/10.1037/cou0000140

Finlay, L. (2002). "Outing" the researcher: The provenance, process, and practice of reflexivity. Qualitative Health Research, 12(4), 531-545. https://doi.org/10.1177/104973202129120052

Haug, E. H. (2016). Kvalitet i norske skolers karriereveiledning: I spennet mellom storsamfunnets behov og elevenes autonomi [Quality in Norwegian schools' career guidance] [Doctoral thesis, Inland Norway University of Applied Sciences]. Lillehammer. http://hdl.handle.net/11250/2444554

Heron, J., \& Reason, P. (2006). The practice of co-operative inquiry: Research "with" rather than "on" people. In P. Reason \& H. Bradbury (Eds.), Handbook of action research: The concise paperback edition (pp. 144-154). Sage.

Heron, J., \& Reason, P. (2008). Extending epistemology within a co-operative inquiry. In P. Reason \& H. Bradbury (Eds.), The Sage handbook of action research: Participative inquiry and practice (2nd ed., pp. 366-380). Sage.

Hooley, T., Sultana, R. G., \& Thomsen, R. (2018). Career guidance for social justice: Contesting neoliberalism. Routledge.

Hummelvoll, J. K. (2008). The multistage focus group interview: A relevant and fruitful method in action research based on a co-operative inquiry perspective. Norsk Tidsskrift for Sykepleieforskning, 10(1), 3-14. http://hdl.handle.net/11250/134226

ILO. (2008). ILO declaration on social justice for a fair globalization. https://www.ivr.uzh.ch/institutsm itglieder/kaufmann/archives/fs13/iel/text46.pdf

Irving, B. A., Borgen, W., \& Højdal, L. (2016). Re/viewing the life-design career paradigm: Critical reflections and re/constructions [Paper]. In: Proceedings of the International Conference of the International Association for Educational and Vocational Guidance, Madrid, Spain.

Irving, B. A., Borgen, W., \& Højdal, L. (2020). Challenging perspectives on the life-design career paradigm: Critical reflections and re/constructions. In B. Malik-Lievano, B. Alvarez-Gonzalez, M. F. Sanchez-Garcia, \& B. A. Irving (Eds.), International perspectives on research in educational and career guidance (pp. 3-15). Springer.

Levin, M. (2017). Aksjonsforskning som forskning: Epistemologiske og metodiske utfordringer [Action research as research: Epistemological and methodological challenges]. In S. Gjøtterud, H. Hiim, D. Husebø, L. H. Jensen, T. H. Steen-Olsen, E. Stjernestrøm, N. Amble, A. Berg, B. Bjønness, \& O. 
Eikeland (Eds.), Aksjonsforskning i Norge: Teoretisk og empirisk mangfold (pp. 27-44). Cappelen Damm Akademisk/NOASP. https://press.nordicopenaccess.no/index.php/noasp/catalog/book/17

Maree, J. G. (Ed.). (2011). Shaping the story: A guide to facilitating narrative career counselling. Sense.

Maree, J. G. (2014). Career construction with a gay client: A case study. British Journal of Guidance \& Counselling, 42(4), 436-449. https://doi.org/10.1080/03069885.2014.886670

Maree, J. G. (2015). Career construction counseling: A thematic analysis of outcomes for four clients. Journal of Vocational Behavior, 86, 1-9. https://doi.org/10.1016/j.jvb.2014.10.001

Maree, J. G. (2016). Career construction counseling with a mid-career black man. Career Development Quarterly, 64(1), 20-34. https://doi.org/10.1002/cdq.12038

Maree, J. G. (2018). Self- and career construction counseling for a gifted young woman in search of meaning and purpose. International Journal for Educational and Vocational Guidance, 19(2), 217 237. https://doi.org/10.1007/s10775-018-9377-2

Maree, J. G., \& Che, J. (2018). The effect of life-design counselling on the self-efficacy of a learner from an environment challenged by disadvantages. Early Child Development and Care, 190(6), 1-17. https://doi.org/10.1080/03004430.2018.1495629

Maree, J. G., \& Crous, S. (2012). Life design career counselling with an abandoned adolescent: A case study. Journal of Psychology in Africa, 22(1), 106-113. https://doi.org/10.1080/14330237.2012. 10874527

McMahon, M. (Ed.). (2017). Career counseling: Constructivist approaches. Routledge.

McMahon, M., \& Watson, M. (2020). Career counselling and sustainable decent work: Relationships and tensions. South African Journal of Education, 40(1), 1-9. https://doi.org/10.15700/saje.v40ns 1a1881

Norendal, K. M. (2018). Life design i Norge: En vei til meningsskaping for individet [Life design in Norway: A path to meaning-making for the individual]. In R. Kjærgård \& P. Plant (Eds.), Karriereveiledning for individ og samfunn (pp. 206-228). Gyldendal Akademisk.

Nota, L., \& Rossier, J. (Eds.). (2015). Handbook of life design: From practice to theory and from theory to practice. Hogrefe.

Parsons, F. (1909). Choosing a vocation. Houghton Mifflin.

Patton, W., \& McMahon, M. (2014). Career development and systems theory: Connecting theory and practice (3rd ed.). Sense.

Plant, P., \& Kjærgård, R. (2016). From mutualism to individual competitiveness: Implications and challenges for social justice within career guidance in neoliberal times. Journal of the National Institute for Career Education and Counselling, 1(36), 12-19.

Reason, P. (2006). Choice and quality in action research practice. Journal of Management Inquiry, 15(2), 187-203. https://doi.org/10.1177/1056492606288074

Rehfuss, M. C., Cosio, S., \& Del Corso, J. (2011). Counselors' perspectives on using the career style interview with clients. The Career Development Quarterly, 59(3), 208-218. https://doi.org/10. 1002/j.2161-0045.2011.tb00064.x

Ribeiro, M. A. (2020). Contributions of psychology to rethinking the decent work concept. Revista Psicologia, 3, 1114-1121. https://doi.org/10.17652/rpot/2020.3.19488

Savickas, M. L. (2013). The 2012 Leona Tyler award address: Constructing careers-Actors, agents, and authors. The Counseling Psychologist, 41(4), 648-662. https://doi.org/10.1177/0011000012468339

Savickas, M. L. (2015a). Career counseling paradigms: Guiding, developing, and designing. In P. J. Hartung, M. L. Savickas, \& W. B. Walsh (Eds.), APA handbook of career intervention (Vol. 1: Foundations) (pp. 129-143). American Psychological Association. https://doi.org/10.1037/14438-008.

Savickas, M. L. (2015b). Life-design counseling manual. http://vocopher.com/LifeDesign/LifeDesign.pdf

Savickas, M. L. (2015c). Life designing with adults: Developmental individualization using biographical bricolage. In L. Nota \& J. Rossier (Eds.), Handbook of life design: From practice to theory and from theory to practice (pp. 135-150). Hogrefe.

Savickas, M. L. (2019a). Career construction counseling manual. M. L. Savickas.

Savickas, M. L. (2019b). Career counseling (2nd ed.). American Psychological Association.

Savickas, M. L. (2021). Career construction theory and counseling model. In S. D. Brown \& R. W. Lent (Eds.), Career development and counseling: Putting theory and research to work (3rd ed., pp. 165199). Wiley.

Savickas, M. L., Nota, L., Rossier, J., Dauwalder, J.-P., Duarte, M. E., Guichard, J., Soresi, S., Van Esbroeck, R., \& van Vianen, A. E. M. (2009). Life designing: A paradigm for career construction in the 21st century. Journal of Vocational Behavior, 75(3), 239-250. https://doi.org/10.1016/j.jvb. 2009.04.004 
Tian, X., Hou, Z. J., Wang, D., Savickas, S., Chang, X., Cao, Y., \& Jia, Y. (2020). Counselor actions to facilitate client change during life-design counseling. The Career Development Quarterly, 68(1), 48-62. https://doi.org/10.1002/cdq.12212

Tien, H.-L.S. (2015). Cultural perspectives on life design. In L. Nota \& J. Rossier (Eds.), Handbook of life design: From practice to theory and from theory to practice (pp. 249-267). Hogrefe.

Winslade, J. (2011). Constructing a career narrative through the care of the self. In K. G. Maree (Ed.), Shaping the story: A guide to facilitating narrative career counselling (pp. 52-62). Sense.

Publisher's Note Springer Nature remains neutral with regard to jurisdictional claims in published maps and institutional affiliations. 